\title{
VOLTAIRE, Taccuino di pensieri. Vademecum per l'uomo
}

\section{Riccardo Campi}

\section{(2) OpenEdition \\ Journals}

\section{Edizione digitale}

URL: https://journals.openedition.org/studifrancesi/31753

DOI: 10.4000/studifrancesi.31753

ISSN: 2427-5856

\section{Editore}

Rosenberg \& Sellier

\section{Edizione cartacea}

Data di pubblicazione: 1 août 2020

Paginazione: 404-405

ISSN: 0039-2944

\section{Notizia bibliografica digitale}

Riccardo Campi, «voltalRe, Taccuino di pensieri. Vademecum per l'uomo», Studi Francesi [Online], 191 (LXIV | II) | 2020, online dal 01 septembre 2020, consultato il 17 septembre 2021. URL: http:// journals.openedition.org/studifrancesi/31753 ; DOI: https://doi.org/10.4000/studifrancesi.31753

Questo documento è stato generato automaticamente il 17 septembre 2021.

\section{(c) (i) $९$}

Studi Francesi è distribuita con Licenza Creative Commons Attribuzione - Non commerciale - Non opere derivate 4.0 Internazionale. 


\title{
VOLTAIRE, Taccuino di pensieri. Vademecum per l'uomo
}

\author{
Riccardo Campi
}

\section{NOTIZIA}

voltaiRE, Taccuino di pensieri. Vademecum per l'uomo, a cura di D. Felice. Prefazione di E.

Ferrero, Milano-Udine, Mimesis, 2019, 540 pp.

1 Per un eccesso di modestia, Domenico Felice ha intitolato il volume di oltre cinquecento pagine, che ha allestito raccogliendo una scelta di aforismi di Voltaire, traendoli tanto dalle opere più celebri che da quelle frequentate dai soli specialisti, Taccuino di pensieri. In realtà, le dimensioni del volume, edito da Mimesis nella collana «Filosofie», non sono affatto quelle del "taccuino"; i criteri adottati nella scelta e il modo accurato nel quale i materiali sono stati disposti nel volume, fanno poi sì che quello che viene offerto al lettore italiano sia, piuttosto, un vero e proprio "dizionario" del pensiero voltairiano. Il volume ha il pregio di presentare, ordinate per temi, migliaia di citazioni, più o meno ampie o folgoranti, tratte da testi appartenenti a ogni genere di scrittura - dai racconti filosofici ai dialoghi, dalle tragedie ai libelli polemici, dalle opere storiche a quelle di divulgazione scientifica, dalle poesie d'occasione ai poemi didascalici, senza dimenticare l'inesauribile fonte della corrispondenza (il vero capolavoro di Voltaire, secondo il giudizio di Lytton Strachey): la quindicina di pagine contenenti la lista dettagliata delle fonti su cui ha lavorato il curatore, traducendole spesso per la prima volta in italiano, testimonia della rappresentatività della scelta compiuta. Ogni singola voce, per giunta, è arricchita da utilissimi rimandi interni ad altre voci tematicamente affini: in questo modo, viene data al lettore volenteroso la possibilità di costruirsi percorsi di lettura obliqui e alternativi, seguendo i propri interessi e le proprie curiosità. In breve, il risultato ottenuto disponendo le voci in ordine alfabetico per temi e creando questa laboriosa trama di riferimenti interni è che il lettore può utilizzare 
questo voluminoso "taccuino" come un atlante di comoda consultazione per orientarsi nel ricco e complesso pensiero voltairiano.

2 Benché Domenico Felice, profondo conoscitore del pensiero francese settecentesco, e in particolare dell'opera di Montesquieu, abbia idee e convinzioni sue proprie riguardo a Voltaire, nonché propri gusti e interessi personali, la sua scelta dei temi e delle "voci", e delle relative citazioni che compongono il volume, non è affatto umorale né tantomeno arbitraria, rispondendo all'esigenza di offrire al lettore un quadro vario e coerente dei molteplici argomenti che stimolarono la riflessione o, per meglio dire, l'esprit di Voltaire. Così, oltre alle immancabili "voci" sulla tolleranza e il fanatismo, il lettore ne troverà centinaia d'altre su ogni sorta di questioni concernenti la filosofia, la politica e le sue istituzioni, la morale e la storia, la letteratura e le civiltà antiche e orientali, nonché altre ancora dedicate a singoli personaggi storici, a poeti e a filosofi, da Aristotele, Confucio e Marco Aurelio a Galileo, Pietro il Grande e John Locke. Impossibile enumerarle tutte: il glossario in cui, alla fine del volume, esse sono elencate in ordine alfabetico occupa sette pagine fitte in doppia colonna; esso costituisce un altro utile strumento per orientarsi all'interno del volume. Le innumerevoli citazioni riguardanti le religioni, quelle giudaica e cristiana in particolare, i profeti, i dogmi della teologia e le superstizioni, i miracoli, oracoli e riti di diversa natura, forniscono un quadro ampio, anche se non esaustivo, di quelli che furono gli interessi, le curiosità, $i$ bersagli polemici di Voltaire.

Questa imponente scelta di citazioni, in cui più viva pare essersi conservata la voce del Patriarca di Ferney, ci conferma che, come osserva Ernesto Ferrero nelle brillanti pagine introduttive, «sono tanti i pensieri in cui ci sembra che Voltaire parli proprio al nostro orecchio». A giusta ragione, Ferrero insiste sull'attualità del pensiero voltairiano nel quale, senza alcuna esagerazione, vede, nel suo complesso, «un presidio civile da riconquistare e difendere». Avendo tuttavia cura di far presente che occorre guardarsi dal credere che per "riconquistare e difendere" il pensiero di Voltaire basti, oggi, ripeterne le battute come slogan o parole d'ordine pronte all'uso, o scimmiottare gli slanci polemici del Patriarca di Ferney contro gli eterni abusi del potere, civile o religioso che sia. Così facendo, si contribuirebbe a ridurre il pensiero e le parole di Voltaire a luoghi comuni e vuoti clichés. Non si tratta più di sposarne la causa come se fosse ancora la nostra. La perdurante attualità dell'opera di Voltaire, che sembra "parlare proprio al nostro orecchio», osserva Ferrero, risiede piuttosto nella nostra capacità di ritrovare in essa e fare nostro l'atteggiamento critico che Voltaire seppe sempre assumere, senza pregiudizi, al cospetto di qualunque argomento o problema con cui l'attualità dei suoi tempi lo costringeva a confrontarsi.

4 Ciò che tanti aforismi ricavati dai suoi testi insegnano è quella che Foucault chiamò «l'arte dell'indocilità ragionata»: dandocene l'esempio concreto, Voltaire insegna a chiedere sempre ragione delle regole, delle leggi, delle credenze e delle tradizioni che ci vengono imposte; questo per contestare ogni autorità di cui solo la forza, la consuetudine o una subdola persuasione occulta, e non la ragione e il buon senso, abbiano sancito la presunta autorevolezza. È questa autorità che viene costantemente messa in dubbio da Voltaire, anche se egli sa bene che «il dubbio non è molto piacevole, la certezza è sempre ridicola» e che «soltanto gl'imbecilli sono sicuri di quello che dicono». La fermezza cui Voltaire ci esorta è quindi quella che consiste nell'«esercitare il coraggio dello spirito»; «essa presuppone una decisione illuminata» a differenza dell'ostinazione che, al contrario, «presuppone un certo accecamento». Di questo tipo 
di coraggio oggi (come sempre d'altronde) c'è un estremo bisogno. La lettura di Voltaire contribuisce senz'altro a infondercelo, e lo fa nella maniera più efficace perché, in virtù di uno stile impareggiabile per arguzia e concisione, lo «spirito» di cui egli parla è, in primo luogo, «una festa offerta al pensiero»: è per questo che leggere Voltaire ci dà, almeno finché dura la lettura, l'impressione di sentirci tutti un po' più intelligenti e coraggiosi. 